\title{
Correction to: Association between circulating alpha-1 antitrypsin polymers and lung and liver disease
}

\author{
Alexa Núñez ${ }^{1,2 \dagger}$, Irene Belmonte ${ }^{1 \dagger}$, Elena Miranda ${ }^{3}$, Miriam Barrecheguren $^{1}$, Georgina Farago $^{1}$, Eduardo Loeb ${ }^{4}$, \\ Mònica Pons ${ }^{5}$, Francisco Rodríguez-Frías ${ }^{2,6,7,8}$, Pablo Gabriel-Medina ${ }^{6}$, Esther Rodríguez' , Joan Genescà ${ }^{2,5,7}$, \\ Marc Miravitlles ${ }^{1,2,9^{*}}$ (1) and Cristina Esquinas ${ }^{1,2}$
}

\section{Correction to: Respir Res (2021) 22:244}

https://doi.org/10.1186/s12931-021-01842-5

The original version of this article [1] unfortunately contained a mistake.

The department details for second affiliation were missing in the original publication of the article. It has been added in this correction.

The correct affiliation details should read as

Department of Medicine, Universitat Autònoma de Barceona, Bellaterra, 08193 Barcelona, Spain.

\section{Author details \\ 'Pneumology Department, Hospital Universitari Vall d'Hebron, Vall d'Hebron Institut de Recerca (VHIR), Vall d'Hebron Barcelona Hospital Campus, P. Vall d'Hebron 119-129, 08035 Barcelona, Spain. ' 2 Department of Medicine, Univer- sitat Autònoma de Barcelona, Bellaterra, 08193 Barcelona, Spain. ${ }^{3}$ Department of Biology and Biotechnologies, 'Charles Darwin' and Pasteur Institute - Cenci Bolognetti Foundation, Sapienza University of Rome, Rome, Italy. ${ }^{4}$ Pneu- mology Department, Teknon Medical Center, Barcelona, Spain. ${ }^{5}$ Liver Unit, Department of Internal Medicine, Hospital Universitari Vall d'Hebron, Vall d'Hebron Institut de Recerca (VHIR), Vall d'Hebron Barcelona Hospital Campus, Barcelona, Spain. ${ }^{6}$ Department of Clinical Biochemistry, Hospital Universitari Vall d'Hebron, Vall d'Hebron Barcelona Hospital Campus, Barcelona, Spain.}

${ }^{7}$ Centro de Investigación Biomédica en Red de Enfermedades Hepáticas y Digestivas, (CIBEREHD), Barcelona, Spain. ${ }^{8}$ Clinical Biochemistry Research GroupNall d'Hebron Institut de Recerca (VHIR), Vall d'Hebron Barcelona Hospital Campus, Barcelona, Spain. ${ }^{9}$ Centro de Investigación Biomédica en Red de Enfermedades Respiratorias (CIBERES), Barcelona, Spain.

Published online: 01 November 2021

\section{Reference}

1. Núnez A, Belmonte I, Miranda E, Barrecheguren M, Farago G, Loeb E, Pons M, Rodríguez-Frías F, Gabriel-Medina P, Rodríguez E, Genescà J, Miravitlles M, Esquinas C. Association between circulating alpha-1 antitrypsin polymers and lung and liver disease. Respir Res. 2021;22:244. https://doi.org/ 10.1186/s12931-021-01842-5.

\section{Publisher's Note}

Springer Nature remains neutral with regard to jurisdictional claims in published maps and institutional affiliations.

\footnotetext{
*Correspondence: marcm@separ.es

${ }^{\dagger}$ Alexa Núñez and Irene Belmonte contributed equally and should be considered first authors

1 Pneumology Department, Hospital Universitari Vall d'Hebron, Vall d'Hebron Institut de Recerca (VHIR), Vall d'Hebron Barcelona Hospital Campus, P. Vall d'Hebron 119-129, 08035 Barcelona, Spain

Full list of author information is available at the end of the article
}

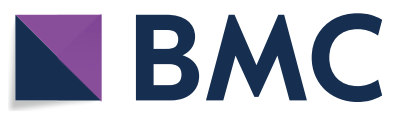

(c) The Author(s) 2021. Open Access This article is licensed under a Creative Commons Attribution 4.0 International License, which permits use, sharing, adaptation, distribution and reproduction in any medium or format, as long as you give appropriate credit to the original author(s) and the source, provide a link to the Creative Commons licence, and indicate if changes were made. The images or other third party material in this article are included in the article's Creative Commons licence, unless indicated otherwise in a credit line to the material. If material is not included in the article's Creative Commons licence and your intended use is not permitted by statutory regulation or exceeds the permitted use, you will need to obtain permission directly from the copyright holder. To view a copy of this licence, visit http://creativecommons.org/licenses/by/4.0/. The Creative Commons Public Domain Dedication waiver (http://creativecommons.org/publicdomain/zero/1.0/) applies to the data made available in this article, unless otherwise stated in a credit line to the data. 